\title{
Working memory capacity, content familiarity, and university EFL students' reading comprehension
}

\author{
Dwi Fita Heriyawati $^{1 *}$, Ali Saukah ${ }^{2}$, and Utami Widiati ${ }^{3}$ \\ Department of English, Faculty Language and Letters, Universitas Kanjuruhan Malang, Malang, East Java, Indonesia ${ }^{1}$ \\ Department of English, Faculty of Letters, Universitas Negeri Malang, Malang, East Java, Indonesia ${ }^{2,3}$
}

\begin{tabular}{|c|c|}
\hline \multirow{2}{*}{\multicolumn{2}{|c|}{$\begin{array}{l}\text { Indonesia, were involved in the study } \\
\text { of at least pre-advanced level. These } \\
\text { the WMC and a multiple-choice readi } \\
\text { there is no interaction effect between } \\
\text { moderator variable; this implies that }\end{array}$}} \\
\hline & \\
\hline $\begin{array}{l}\text { First Received: } \\
19 \text { November } 2017\end{array}$ & $\begin{array}{c}\text { Accepted: } \\
\text { 12 April } 2018\end{array}$ \\
\hline $\begin{array}{l}\text { Final Proof Received: } \\
25 \text { May } 2017\end{array}$ & $\begin{array}{l}\text { Published: } \\
\text { 31 May } 2018\end{array}$ \\
\hline \multicolumn{2}{|c|}{$\begin{array}{l}\text { How to cite (in APA style): } \\
\text { Heriyawati, D. F., Saukah, A., Widiati, U. (2018). Working memory capacity, content } \\
\text { familiarity, and university EFL students' reading comprehension. Indonesian Journal of } \\
\text { Applied Linguistics, } 8(1), 21-27 \text {. doi: } 10.17509 / \text { ijal.v8i1.11458 }\end{array}$} \\
\hline
\end{tabular}

\section{INTRODUCTION}

Reading is generally perceived as the process of recognition and comprehension of written or printed materials. University students are expected to read critically to understand and connect the information in the text thoroughly as well as to help them discover knowledge from the text. Critical reading demands students to make judgments about what they read; as critical readers, therefore, they should know not only what the text says but also how the author expresses the various uniqueness of the text. When the students read critically, they should be able to evaluate, synthesize, and analyze texts which might be reflected by restating, describing, and interpreting the content of the text. Richards and Schmidt (2002, p. 134) define critical reading as "... reading in which the reader reacts critically to what he or she is reading, through relating the content of reading material to personal standards, values, attitudes, or beliefs, such as going beyond what is said in the text and critically evaluating the relevancy and value of what is read".

Similarly, by adopting a social perspective, Carter and Nunan (2002, p. 220) define critical reading as "a reading practice which attends to the ideological underpinning of text, as signaled not so much by what the writer chooses as a topic, but how people, places, and events are talked about". Critical readers perform a mental action on the word form and make associations between the context and their own personal knowledge to infer word meanings (Wallace, 2003). Such mental action appears significant in facilitating readers in making use of their personal knowledge to grasp meaning from the text with the help of context.

An issue related to successful critical reading thus seems to be working memory capacity (WMC). However, as literature suggests, WMC may be differentially affected, depending on whether the reading comprehension is a literal, inferential, or critical

\footnotetext{
* Corresponding author:

Email: dwifita@unikama.ac.id
} 
nature because there could be qualitative differences in the complexity level of the reading tasks involved in each case (Sasaki, 2000), and the degree of activated and reconstructed schematic information stored in longterm memory (LTM). In particular, the more difficult the tasks given to the students are, the more complicated working memory processing is. Alptekin (2009) and Weissheimer (2011) in their research found that unlike recall tasks, recognition tasks fail to detect individual differences in working-memory storage. They further indicate that composite scores of storage and processing correlate with inferential rather than literal understanding in L2 reading when recall-based, rather than recognition-based, reading span tests are used to measure storage. However, only lower span participants had a statistically significant improvement in working memory scores over trials.

Furthermore, the cognitive resources underlying reading as a whole can be associated with the processing and storage functions of WMC. It is important to probe what role WMC plays in reading comprehension, taken in terms of its multilevel representational architecture, particularly with respect to its specific dimensions of literal, inferential, and critical reading. Individual differences in reading comprehension may reflect differences in WMC, especially in the trade-off between its processing and storage functions. A poor reader's processes may be inefficient, so they lessen the amount of additional information that can be maintained in working memory (Daneman \& Carpenter, 1980). Varol and Erçetin, (2016) observed that access to both lexica and topic-level glosses had immediate facilitative effects on word recognition without facilitative delayed effects. They also found that there is a significant relationship of WMC and reading comprehension in relation to the treatment condition and immediate positive effects of glosses on incidental vocabulary learning.

Research in the areas of WMC has investigated a variety of topics, such as the relation between working memory and general intelligence (Conway, Kane, \& Engle, 2003). Significant positive correlations between WMC and language comprehension have been found in numerous L1 studies (Alptekin, 2011). Some research on WMC reveals that such capacity was very essential to help readers understand the content of the text very well. Working memory, with its restricted functions of processing and storage, is said to play an important role in distinguishing efficient and inefficient readers, as indicated by Swanson and his colleagues (Swanson \& Berninger, 1995; Swanson \& Alexander, 1997; Swanson, 1999; Swanson \& Howell, 2001), among others. Research to date suggests that the relationship between WMC and reading comprehension also seems to apply to second language (L2) reading (Harrington \& Sawyer, 1992; Geva \& Ryan, 1993; Miyake \& Friedman, 1998; Leeser, 2007).

Considering the importance of WMC in reading comprehension, Alptekin's (2011) study found that in terms of levels of interactive processing, readers engage first in the linguistic processing of surface level textual features. This process gradually paves the way to the construction of a text microstructure, which further includes relating propositions that are in close proximity in the text so as to form a coherent semantic whole. When readers combine the locally-built semantic wholes, a text base is constructed in the form of a macro structure. The text base, which captures the text internal meaning of the passage, contains the propositions embedded in the sentences and their interrelationships. In addition to text-based procedures involving the surface code (e.g., lexical decoding, word-to-text interpretation, syntactic parsing), the extraction of meanings from sentences, and the gradual accumulation of meanings as a result of processing successive sentences, in text-based construction further involves the generation of inferences that are necessary for discourse coherence. From those findings, it can be inferred that content familiarity (CF) works independently from working memory to improve inferential comprehension in the higher level operation of comprehension, yet content familiarity does not affect lower level operation in the literal comprehension. The finding of Alptekin's research (2011) also indicated that there was no significant effect in WMC and CF on the literal comprehension. This study might be true since literal comprehension is the easiest type of comprehension, so it does not need a particular strategy to understand it. Jahangiri, Soleimani, and Jafarigohar (2017) also stated that there is no relationship between WMC and learning in implicit condition, moreover they also stated that there is significant relationship between WMC and learning difficult linguistic structures in explicit condition.

Another important factor that affects reading comprehension seems to be the degree of interaction between the reader's domain knowledge and textual content, as has been illustrated amply in L2 schema theoretic research (Lee, 2007) as well as in recent construction integration models of comprehension focusing on L1 and on L2 (Nassaji, 2002). When text content and domain knowledge are congruent, L2 readers perform more like efficient $\mathrm{L} 1$ readers. It makes adequate use of both their higher and lower order cognitive operations for comprehension. It follows that L2 readers' familiarity with textual content tends to improve their comprehension, in particular, their inferential understanding, which results from knowledge driven processes (Fincher-Kiefer, 1992). Some findings of the research on $\mathrm{CF}$, whether in the form of simplification or elaboration, focus on their influencing literal and inferential aspects of reading in diametrically-opposed ways. The main point shows that $\mathrm{CF}$ refers to thematically-different texts being simplified, elaborated, or left unmodified. Simplification of the text may improve literal understanding, yet it does not enhance inferential comprehension because some linguistic features might have been removed. In other words, it can be said that richness in details and connections help readers perceive 
implicational links of the text. Then, it can be inferred that the use of elaboration can improve readers' ability to generate inferential meaning from the text. However, as suggested in the study, elaboration may hamper readers' processing of surface-level features, due to the additional information introduced into the text. Similarly, based on their research findings that involved 105 passages from nine textbooks (some authentic and others simplified), Crossley, McCarthy, Louwerse, and McNamara (2007) criticized simplified texts on account of their failure to demonstrate cause and effect relationships and to develop plots and ideas adequately. Elsewhere, elaboration in the form of explanatory notes is shown to help reading comprehension only in the L1, reducing comprehension altogether in the event the reading task is in the L2 (Yeung, Jin, \& Sweller, 1998).

In short, WMC and CF appear to play an important role in the field of education. WMC relates to the ability to mentally store and manipulate information relevant to a task (Baddeley, 1986, 2003). This is also relevant to the ability to store and process information, two important factors in the process of teaching and learning. Students need to understand instructions from their teachers; they must comprehend the content of learning materials tasks. Students' ability in comprehending reading text is important in the field of education. Another part of WMC is central executive that has also been shown to relate reading comprehension and global verbal abilities (e.g., Daneman \& Carpenter, 1980; Turner \& Engle, 1989). Furthermore, an investigation of the combined effects of WMC and CF on two different dimensions of reading is essential because in this area they still remain largely unexplored, at least to the best of the researchers' knowledge. Whether reading performance is affected by WMC limitations with or without the role played by domain knowledge and CF should offer important implications.

Referring to the previous description, this study examines the effect of WMC and CF on inferential and critical comprehension of EFL reading text. These contributions already influence $\mathrm{L} 1$ reading text, but in this case we are curious to know whether they have positive contribution in the inferential and critical EFL reading comprehension. In particular, this study addresses the following research questions:

1. Does working memory capacity (WMC) affect EFL reading comprehension?

2. Does content familiarity (CF) affect EFL reading comprehension?

3. Is there any interaction between WMC and $\mathrm{CF}$ in EFL reading comprehension?

\section{METHOD}

This quantitative research involved seventy senior students of a private university in Malang; they had been selected based on their English proficiency, which was at least of a pre-advanced level. They had passed all the reading courses offered in their undergraduate
English education study program at the university. We assumed that the students had sufficient knowledge to understand various types of texts, including expository ones. Three research instruments were employed to collect the data; they were a reading span test (RST) to measure WMC, a collection of reading texts to measure $\mathrm{CF}$, and a reading comprehension test in the form of multiple-choice items to measure reading comprehension. The reading span test, presented in a computerized version, was developed by Daneman and Carpenter (1980) and intended to determine the students' memory storage. The results of the tests were shown in the screen by the end of the test. In terms of WMC, the students were then categorized into two groups: HWMC (High working memory capacity) and LWMC (low working memory capacity).

CF was indicated by the students' opinions about whether they were familiar or not familiar with the texts. A collection of expository texts was used to elicit the students' own culture and background knowledge. Furthermore, a multiple-choice reading test was given to know the students' reading ability in comprehending the texts. The multiple-choice test items consisted of four options designed based on the criteria for constructing reading comprehension questions, comprising items related to inferential and critical comprehension. However, the students' performance in the reading test was indicated by one score of reading comprehension, not separating the inferential and the critical items. The students were instructed to read the text on the computer screen and to answer the questions, which appeared one by one after each text. The texts could be scrolled separately from the questions. The students' correct answers were recorded directly, and at the end of the test, they directly knew their own score.

The data obtained from $\mathrm{WMC}, \mathrm{CF}$, and the reading multiple choice test were analyzed by using two-way ANOVA to examine the interactional effects of the three variables under investigation.

\section{FINDINGS}

Before examining the impacts of $\mathrm{WMC}$ and $\mathrm{CF}$ on reading comprehension, we considered it necessary to probe on the normal distribution of the data. Through the application of Kolmogorov-Smirnov $Z$ statistical analysis, it was discovered that the p-value is 0.20 , which is greater than 0.05 . This value means that the data reflect normal distribution; in other words, the normality of the data meets the requirement. An examination of the descriptive statistics for all variables can be seen in Table 1 .

Table 1. Descriptive Statistics of All Variables Dependent Variable: Reading

\begin{tabular}{llccc}
\hline & & Mean & Std. Deviation & N \\
\hline CF & Familiar & 20.57 & 6.05 & 70 \\
& Unfamiliar & 16.68 & 4.29 & 70 \\
& & & & \\
WMC & High & 22.29 & 4.59 & 70 \\
& Low & 14.02 & 2.32 & 70 \\
\hline
\end{tabular}


WMC and EFL Students' Reading Comprehension Referring to the first research question, results from the data analysis indicate that WMC affects students' reading comprehension. Based on the test results, students' scores can be categorized into two: high WMC (HWMC) for the scores of 60 and above and low WMC (LWMC) for the scores of 59 and below. To investigate the interaction effect among the variables, the researchers applied a two-way ANOVA. Results from the computation, in the table of distribution $\mathrm{F}$, showed that the F-value from the table with degrees of freedom (df) $n 1=1$ and $n 2=136$ is 3.91 . Then, it can be inferred that the obtained F-value is greater than the F-value from the table $(283.73>3.91)$ suggesting that WMC affects he students' reading comprehension; the HWMC students obtained higher scores of reading comprehension.

CF and EFL Students' Reading Comprehension

The statistical computation to determine the effect of $\mathrm{CF}$ on the students' reading comprehension, as the focus of the second research question, reveals that F-value in the table of distribution $F$ with the degrees of freedom (df) $\mathrm{n} 1=1$ and $\mathrm{n} 2=136$ is 3.9107 . The obtained F-value in the result of computation is greater than the F-value from the table $(51.64>3.91)$. As for the p-value, it is 0.00 . The p-value compared with significant level 0.05 is less than 0.05. These computations mean that $\mathrm{CF}$ affects reading comprehension. Regarding the unfamiliar texts, the results of the reading comprehension test show that the lowest score was 7 , and the highest score was 25 , with the mean and standard deviation of 16.68 and 4.29 respectively. In contrast, for the familiar texts, the results show that the lowest score was 12, and the highest score was 33 with, the mean and standard deviation of 20.57 and 6.04 respectively. Those statistical figures suggest that the more familiar the students with the texts they are reading, the better their reading performance is.

Table 2. Test of Between-subjects Effects for WMC and CF

Dependent Variable: Reading

\begin{tabular}{lcrrrr}
\hline \multicolumn{1}{c}{ Source } & $\begin{array}{c}\text { Type III Sum of } \\
\text { Squares }\end{array}$ & df & Mean Square & F & Sig. \\
\hline Corrected Model & $8.69 \mathrm{a}$ & 3 & 2.89 & 113.427 & 0.00 \\
Intercept & 1126.34 & 1 & 1126.34 & 44080.739 & 0.00 \\
Familiarity & 1.32 & 1 & 1.32 & 51.647 & 0.00 \\
WM & 7.25 & 1 & 7.25 & 283.730 & 0.00 \\
Familiarity*WM & 0.04 & 1 & 0.04 & 1.900 & 0.17 \\
Error & 3.47 & 136 & 0.02 & & \\
Total & 1174.44 & 140 & & & \\
Corrected Total & 12.170 & 139 & & & \\
\hline
\end{tabular}

WMC, CF, and EFL Students' Reading Comprehension

In the final analysis, the quantitative evidence in response to the third research question is not statistically significant. From the analysis, it was found that F-value from the table in the table of distribution $\mathrm{F}$ with the degrees of freedom (df) $\mathrm{n} 1=1$ and $\mathrm{n} 2=136$ is 3.91 . The obtained F-value from the result of computation is compared with the F-value from the table, which shows that the obtained F-value is lower than F-value from the table $(1.90<3.91)$. In addition, $p$-value is 0.17 . The $p$ value compared with the significant level of 0.05 is greater than 0.05. Based on the results of the statistical computation, it can be inferred that the effect of WMC did not depend on CF. This means that WMC and CF together did not affect the students' reading comprehension. WMC and CF operate independently, and their effects on reading comprehension are additive rather than interactive. In conclusion, regardless of the level of students' WMC, they can comprehend a text better when they are familiar with it.

\section{DISCUSSION}

The interpretation of the findings can be based primarily on the main effect of each independent variable on students' reading comprehension. The effect of WMC on students' reading comprehension is different from that of CF on students' reading comprehension. As the participants in the present study showed homogeneous proficiency in foreign language use, handling explicit textual features did not result in an excessive amount of cognitive load for either group's working memory, which as a matter of fact is considered an important determiner of syntactic comprehension (Miyake \& Friedman, 1998, p. 346). Meanwhile, considering the vital role of working memory in undertaking complex cognitive operations such as drawing inferences (Singer \& Ritchot, 1998), the high span readers who evidently transcends sentence comprehension, have better comprehension in integrating information across sentences and generating inferences. This is consistent with the observation by Miyake and Friedman's (1998: $345)$ that the impact of the ability of working memory constraints becomes more evident between individuals with high and low spans when they perform complex tasks that put a heavy load on WMC.

Moreover, based on Koda's (2005, pp. 199-200) argument of the possibility of using tasks to measure WMC and also similar or even identical abilities in reading, one can argue that inferential reading activity and and working memory processing demonstrate 
similar to higher order cognitive operations. In reality, one positive relationship between the capacity of working memory and inferential comprehension is not the case for critical understanding. In view of this shared variance or perhaps overlap, it is a predated conclusion that, if one expects a correlation between the capacity of working memory and one of the two dimensions underlying reading, there is a high probability that the dimension is inferential comprehension.

Individual differences in working memory have been shown to affect the ability to integrate information, to find the referent for a pronoun, to watch for semantic inconsistencies between texts, to solve lexical ambiguity, to abstract a main theme, to draw comparisons, and to function well on general measures of comprehension (Carpenter, Miyake \& Just, 1994; Daneman \& Green, 1986). Regarding language acquisition, working memory has been found to play a major part in the acquisition of new vocabulary and in more global measures of acquisition. Daneman and Green (1986) found that it plays a significant role in determining how easily readers infer word meanings from context. Noting that readers use context to enrich their understanding of words that are only partly known, Daneman and Green (1986) also proposed that working memory may facilitate vocabulary growth in an indirect manner.

EFL learners with a high memory span were able to learn new words in the three times in RST, whereas learners with a low span took more than five times to do the same task. Thus, prior to making any strong claims for the centrality of working memory to language comprehension and acquisition, it is of utmost importance that the validity of the construct is established by demonstrating its independence from intelligence and proficiency. Furthermore, in the case of foreign language acquisition, it will be important to understand the relation between the working memory of L1 and L2. The evidence regarding working memory and intelligence tends to impress independent constructs for L2 learning. They are simply the intake that the various processing strategies in working memory, in conjunction with information from long-term memory, work to create meaning known as dynamic multicomponential WMC (Baddelay, 2003). The effectiveness of WMC is then measured by asking the participants to complete a reading comprehension test acknowledged internationally.

Based on the results of this study, one can infer that CF (familiar and unfamiliar texts) influences the readers' comprehension. The significant results of this study argue that $\mathrm{CF}$ and students' reading comprehension show that the students comprehend familiar reading texts better because they have sufficient background knowledge of the content of the texts.

It is important to explore students' WMC with regard to their ability in understanding the content of the text. Students with high WMC use their language knowledge (e.g. semantic and syntactic) to predict words from sentence cues or to predict meaning; they have enough linguistic knowledge and background knowledge to read and understand the text without considerable difficulty. In contrast, students with low WMC lack the prior knowledge that renders it difficult for them to understand the content of the text. As a result, the conclusion that we can draw is that regardless of their level of WMC, students comprehend the text better when they are familiar with the content of the text.

The third objective of the study was to investigate the combined effects of WM capacity and CF on reading comprehension. Students' WMC and CF do not affect their reading comprehension at the same time. Students have good comprehension of the content of reading text when they are familiar with it. The conclusion regarding the lack of interaction between WMC and CF is consistent with the research findings of Hambrick and Engle (2002). It is also in line with the results of the research conducted by Payne, Kalibatseva, and Jungers (2009) that is, another piece of evidence for the independent influence of domain knowledge and WMC on reading comprehension, which was based on the dependent variable being measured through multiple-choice questions (as in the present study).

\section{CONCLUSION}

This study shows that there is no significant interaction between WMC and CF in affecting the students' reading comprehension. Students who have higher WMC can comprehend texts better than students who have lower WMC, regardless of whether they are familiar or not with the texts. In relation to the role of CF in students' reading comprehension, we find that $\mathrm{CF}$ contributes to the students' reading comprehension. The more familiar the students with the content of the texts are, the better they understand the texts. If the students are not familiar with the texts, they will find difficulties comprehending the texts.

\section{ACKNOWLEDGMENTS}

This research was supported by a grant scholarship BPPDN for DFH 2012-2016 from the Minister of Directorate Higher Education of Indonesia.

\section{REFERENCES}

Alptekin, C. (2009). Assessing the relationship of working memory to L2 reading: Does the nature of comprehension process and reading span task make a difference? System 37, 627-639.

Alptekin, C. (2011). Effect of working memory capacity and content familiarity in L2 reading comprehension. TESOL Quarterly, 45(2), 235-266.

Baddeley, A., D. (1986). Working memory. Oxford, England: Clarendon Press. 
Baddeley, A., D. (2003). Working memory and language: An overview. Journal of Communication Disorders, 36, 189-208.

Carpenter, P., A., Miyake, A., \& Just, M., A. (1994). Working memory constraints in comprehension. In M. A. Gernsbacher (Ed.), Handbook of psycholinguistics (pp. 1075-1122). San Diego, CA: Academic Press.

Carter, R., \& Nunan, D. (2002). The Cambridge guide to teaching English to speakers of other languages. Cambridge: Cambridge University Press.

Conway, A. R. A., Kane, M. J., \& Engle, R. W. (2003). Working memory capacity and its relation to general intelligence. Trends in Cognitive Sciences, 7, 547-552.

Crossley, S., A., McCarthy, P., M., Louwerse, M. M., \& McNamara, D. S. (2007). A linguistic analysis of simplified and authentic texts. The Modern Language Journal, 91, 15-30.

Daneman, M., \& Carpenter, P. (1980). Individual differences in working memory and reading. Journal of Verbal Learning and Verbal Behavior, 19, 450-466.

Daneman, M., \& Green, I. (1986). Individual differences in comprehending and producing words in context. Journal of Memory and Language, 25, 1-18.

Fincher-Kiefer, R. (1992). The role of prior knowledge in inferential processing. Journal of Research in Reading, 15, 12-27.

Geva, E., \& Ryan, E. B. (1993). Linguistic and cognitive correlates of academic skills in first and second languages. Language Learning, 43, 5-42.

Hambrick, D. Z., \& Engle, R. W. (2002). Effects of domain knowledge, working memory capacity, and age on cognitive performance: An investigation of the knowledge-is-power hypothesis. Cognitive Psychology, 44, 339-387.

Harrington, M., \& Sawyer, M. (1992). L2 working memory capacity and L2 reading skill. Studies in Second Language Acquisition, 14, 25-38.

Jahangiri, K., Soleimani, H., \& Jafarigohar, M. (2017). Working memory capacity and learning L2 structures under explicit and implicit condition: The effect of type of linguistic structures. Language Related Research, 8(2), 77-100.

Koda, K. (2005). Insights into second language reading: A cross-Linguistic approach. New York, NY: Cambridge University Press.

Lee, S. (2007). Effects of textual enhancement and topic familiarity on Korean EFL students' reading comprehension and learning of passive form. Language Learning, 57, 87-118.

Leeser, M. J. (2007). Learner-based factors in L2 reading comprehension and processing grammatical form: Topic familiarity and working memory. Language Learning, 57, 229-270.

Miyake, A., \& Friedman, N. P. (1998). Individual differences in second language proficiency:
Working memory as language aptitude. In A. F. Healy \& L. E. Bourne (Eds.), Foreign language learning: Psycholinguistic studies on training and retention (pp. 339-364). Mahwah, NJ: Lawrence Erlbaum.

Nassaji, H. (2002). Schema theory and knowledgebased processes in second language reading comprehension: A need for alternative perspectives. Language Learning, 52, 439-481.

Payne, T. W., Kalibatseva, Z., \& Jungers, M. K. (2009). Does domain experience compensate for working memory capacity in second language reading comprehension? Learning and Individual Differences, 19, 119-123.

Richards, J. C., \& Schmidt, R. (2002). Longman dictionary of language teaching and applied linguistics ( $3^{\text {rd }}$ Ed.). London: Pearson Education.

Sasaki, M. (2000). Effects of cultural schemata on students' test taking processes for cloze tests: A multiple data source approach. Language Testing, 17, 85-114.

Singer, M., \& Ritchot, K. F. M. (1996). The role of working memory capacity and knowledge access in text inference processing. Memory \& Cognition, 24, 733-743.

Swanson, H. L. (1999). Reading comprehension and working memory in learning-disabled readers: Is the phonological loop more important than the executive system? Journal of Experimental Child Psychology, 72, 1-31.

Swanson, H. L., \& Alexander, J. E. (1997). Cognitive processes as predictors of word recognition and reading comprehension in learning-disabled and skilled readers: Revisiting the specificity hypothesis. Journal of Educational Psychology, 89, 128-158.

Swanson, H. L., \& Berninger, V. (1995). The role of working memory in skilled and less skilled readers' comprehension. Intelligence, 21, 83-108.

Swanson, H. L., \& Howell, M. (2001). Working memory, short-term memory, and speech rate as predictors of children's reading performance at different ages. Journal of Educational Psychology, 93, 720-734.

Turner, M. L., \& Engle, R. W. (1989). Is working memory capacity task dependent? Journal of Memory and Language, 28, 127-154.

Varol, B., \& Erçetin, G. (2016). Effects of working memory and gloss type on L2 text comprehension and incidental vocabulary learning in computer-based reading. Procedia of Social and Behavioral Sciences, 232, $759-768$.

Wallace, C. (2003). Critical reading in language education. New York: Palgrave Macmillan.

Weissheimer, J. (2011). The role of working memory capacity in the development of L2 speech production. Ilha do Desterro: A Journal of English Language, Literatures in English and Cultural Studies, 60, 75-104. 
Indonesian Journal of Applied Linguistics, 8(1), May 2018

Yeung, A. S., Jin, P., \& Sweller, J. (1998). Cognitive load and learner expertise: Split-attention and redundancy effects in reading with explanatory notes. Contemporary Educational Psychology, 23, $1-21$. 